\title{
A prospective study of combination of TOT with various modes of hysterectomy
}

\author{
Aditi Phulpagar ${ }^{1}$, Prasad Yeshwant Deshmukh ${ }^{2 *}$
}

\begin{abstract}
${ }^{1}$ Department of Obstetrics and Gynaecology, K. B. Bhabha Municipal General Hospital, Bandra, Mumbai, Maharashtra, India

${ }^{2}$ Department of Obstetrics and Gynaecology, Lokmanya Tilak Municipal General Hospital, Sion, Mumbai, Maharashtra, India
\end{abstract}

Received: 21 February 2017

Revised: 25 February 2017

Accepted: 09 March 2017

\section{*Correspondence:}

Dr. Prasad Yeshwant Deshmukh,

E-mail: drpydeshmukh@gmail.com

Copyright: (c) the author(s), publisher and licensee Medip Academy. This is an open-access article distributed under the terms of the Creative Commons Attribution Non-Commercial License, which permits unrestricted non-commercial use, distribution, and reproduction in any medium, provided the original work is properly cited.

\begin{abstract}
Background: The present study aimed to evaluate the efficacy of transobturator tape (TOT) in patients with urodynamic stress incontinence (USI) and advanced genital prolapsed with various modes of Hysterectomy.

Methods: It is a retrospective study, carried out in the duration November 2013 to September 2016. All patients from Gynecological OPD of K B Bhabha General Hospital were recruited for the present study.

Results: Data was analyzed using SPSS 21.0 (SPSS Inc., Chicago, IL, USA) using appropriate statistical tests.

Conclusions: TOT is equally effective alone and in combination of any mode of hysterectomy, provided the surgeon is experienced enough with required expertise.
\end{abstract}

Keywords: Post hysterectomy vault prolapse, Stress urinary incontinence, Total abdominal hysterectomy, Total laparoscopic hysterectomy, Transobturator tape, Vaginal hysterectomy

\section{INTRODUCTION}

Stress urinary incontinence (SUI) has a significant impact on the quality of life for many women, although estimates of prevalence vary widely due to inconsistencies in the definitions of SUI and differences in populations studied. An estimated prevalence for urinary incontinence is nearly $30 \%$ in women aged $30-60$ years, with approximately half of the cases attributed to SUI, as per Te Linde's book of Operative Gynaecology. The treatment for SUI has various modalities, which include conservative treatment in first go like Kegel's exercises, bladder training, maintaining bladder diary and subsequently surgery, which is an option for women whose quality of life is still impaired after a diagnosis of genuine stress incontinence has been confirmed.
In 1998, Nickel et al from Holland reported a successful sling procedure using a polyester ribbon passed through the obturator foramen and around the urethra for treatment of refractory urethral sphincter incompetence in female dogs. In France in 2001, Delorme introduced the transobturator sling procedure in humans. Thousands of procedures have been performed in Europe and more recently in the United States, and nowadays this newer, safer approach to the tension free tape sling procedure has picked up in India.

In transobturator tape (TOT) placement, through small incisions placed in the groins and in the vagina under the urethra, the mesh can be placed under the urethra in the correct position without having to pass needles blindly through the retropubic space, as in transvaginal tape 
(TVT). The space that the needle passes through has been extensively studied and has been found to be a very safe space to work in. The mean operative time is significantly shorter in the transobturator sling and risk of bladder injury and of postoperative urinary retention is also considerably lower than other sling procedures. The TOT is a tensionfree sling as the resting urethral angle is not changed by the procedure, nor is it necessary to correct urethral hypermobility. One of the most important and not wellrecognized advantages of the TOT as compared with other mid-urethral sling procedures is the lower rate of de novo urge/urge incontinence. As far as sexual activity is concerned, there is no significant change in patients' sexual life as regard frequency of intercourse and pleasure and/or pain during penetration, whereas there is a significant decrease in coital incontinence. ${ }^{1}$

\section{METHODS}

It is a retrospective study, carried out in the duration November 2013 to September 2016. All patients from Gynecological OPD of K B Bhabha General Hospital were recruited for the present study. All patients undergoing the procedure were completely evaluated with presenting history, general examination and local examination to look for stress incontinence. All women were evaluated to rule out components of cystitis and detrusor instability. Urodynamic evaluation was not done in all patients as the facility is not available in our setup. It was operator's protocol to assess every patient in terms of stress, infective and detrusor component separately. For stress component, it was mandatory to demonstrate stress component on at least 2 occasions with full bladder. For ruling out infective component, it was mandatory to get a urine culture to be normal in immediate pre-operative phase. Detrusor component had been treated by Tab Darifenacin $(2.5 \mathrm{mg})$ three times a day.

As per authors personal experience, outside in technique has been found to be better in terms of technical ease, better ergonomics, blood loss and post-surgical outcome.

If stress incontinence was not demonstrable at more than 2 occasions on full bladder, then the procedure was deferred.

TOT procedure was performed in combination of total abdominal hysterectomy, total laparoscopic hysterectomy, vaginal hysterectomy, and in post-hysterectomy cases as well. However, results were not significantly affected by any of the above combination, when case selection has been done judiciously.

Patient need not be counseled aggressively, so as to affect her psyche in terms of post-operative complications, like retrograde urethral dilatation.

The inclusion and exclusion criteria were set as mentioned in above discussion.
Data was analyzed using SPSS 21.0 (SPSS Inc., Chicago, IL, USA) using appropriate statistical tests.

\section{RESULTS}

Mean age of the subjects in present study was 46.15 years with $60 \%$ of them were between $41-50$ years of age (Table 1).

Table 1: Number of patients showing age group distribution.

\begin{tabular}{|c|c|c|}
\hline Age group (yrs) & $\mathbf{N}$ & $\%$ \\
\hline $31-40$ & 7 & $17.5 \%$ \\
\hline $41-50$ & 24 & $60.0 \%$ \\
\hline $51-60$ & 9 & $22.5 \%$ \\
\hline Total & 40 & $100.0 \%$ \\
\hline
\end{tabular}

Most of the females $(90 \%)$ were multipara with $17.5 \%$ had more than 5 children (Table 2).

Table 2: Parity of patients.

\begin{tabular}{|l|l|l|}
\hline Parity & N & $\%$ \\
\hline Primi & 4 & $10.0 \%$ \\
\hline 2 to 5 & 29 & $72.5 \%$ \\
\hline$>5$ & 7 & $17.5 \%$ \\
\hline Total & 40 & $100.0 \%$ \\
\hline
\end{tabular}

Trans-obturator Tape (TOT) procedure along with hysterectomy was performed in $80 \%$ of the subjects while TOT alone was performed in $20 \%$ patients. Vaginal hysterectomy (22/32) was the most common procedure performed (Table 3).

Table 3: Modes of hysterectomy.

\begin{tabular}{|ll|l|}
\hline Hysterectomy & $\mathbf{N}$ & $\%$ \\
\hline Abdominal & 4 & $10.0 \%$ \\
\hline Laparoscopic & 5 & $12.5 \%$ \\
\hline Vaginal & 22 & $55.0 \%$ \\
\hline Post Hysterectomy & 1 & $2.5 \%$ \\
\hline No Hysterectomy & 8 & $20.0 \%$ \\
\hline Total & 40 & $100.0 \%$ \\
\hline
\end{tabular}

In majority of the cases $(62.5 \%)$ hospital stay was less than 7 days (mean 6.2 days) while stay of more than 14 days was seen in only 1 case (Table 4).

Table 4: Number of days of hospital stay.

\begin{tabular}{|c|c|c|}
\hline Hospital Stay (days) & $\mathbf{N}$ & $\%$ \\
\hline$<7$ days & 25 & $62.5 \%$ \\
\hline 7-14 days & 14 & $35.0 \%$ \\
\hline$>14$ days & 1 & $2.5 \%$ \\
\hline Total & 40 & $100.0 \%$ \\
\hline
\end{tabular}

\section{Data analysis}


Post-op pain and discharge was seen in only $3(7.5 \%)$ and $2(5 \%)$ cases respectively while burning micturition was observed in $5 \%$ cases. No post-op complication was observed in majority (75\%) of the cases (Table 5). All the cases were completely dry at 1 year postoperative follow up.

Table 5: Complications.

\begin{tabular}{|lll|}
\hline Complications & N & $\%$ \\
\hline Burning micturation & 2 & $5.0 \%$ \\
\hline Cough & 1 & $2.5 \%$ \\
\hline Calculi & 1 & $2.5 \%$ \\
\hline Fibroid & 1 & $2.5 \%$ \\
\hline Pain & 3 & $7.5 \%$ \\
\hline White Discharge & 2 & $5.0 \%$ \\
\hline None & 30 & $75.0 \%$ \\
\hline Total & $\mathbf{4 0}$ & $\mathbf{1 0 0 . 0 \%}$ \\
\hline
\end{tabular}

\section{DISCUSSION}

Over the past few years, a substantial increase in the number of surgeries for pelvic organ prolapse (POP) and incontinence was observed due to the aging population and rising incidence of pelvic floor disorders. ${ }^{2}$ The goal of prolapse/ anti-incontinence surgery is to correct associated pelvic symptoms and to improve quality of life. ${ }^{3}$ Continence is achieved by primarily two mechanisms with the sling procedure. The sling creates a stable backboard for the urethra to close upon, and upward displacement or mechanical kinking of the sling occurs with increased abdominal pressure. Synthetic mid-urethral slings, specifically the tension-free vaginal tape (TVT) procedure, were developed in the late-1990s and have gained significant popularity since their inception. ${ }^{4}$ Transobturator (TOT) mid-urethral slings were developed after the TVT. The transobturator approach was developed to minimize the potential for bladder and bowel injuries associated with the retropubic sling, since the sling is passed through the obturator foramen, avoiding the pelvic organs in the retropubic space. ${ }^{5}$ Recent evidence suggests that the subjective success rate and postoperative urge urinary incontinence rate following TOT procedures are comparable to those of TVT; however, the rate of voiding dysfunction are lower with TOT. ${ }^{6}$ The present study aimed to evaluate the efficacy of transobturator tape (TOT) in patients with urodynamic stress incontinence (USI) and advanced genital prolapsed with various modes of Hysterectomy.

In present study TOT procedure, along with hysterectomy was performed in $80 \%$ of the subjects while TOT alone was done in remaining $20 \%$ subjects. Mean hospital stay in our patients was 6.2 days. Post-op pain and discharge was seen in only $3(7.5 \%)$ and $2(5 \%)$ cases respectively while burning micturition was observed in $5 \%$ cases. No post-op complication was observed in majority $(75 \%)$ of the cases. All the cases were completely dry at 1 year postoperative follow up. This shows that TOT is very effective in controlling incontinence symptoms and is equally effective alone and in combination of any mode of hysterectomy.

In a similar study by Lo TS et al., 57 females with urodynamic stress incontinence (USI) and advanced genital prolapse were managed by TOT along with other procedures. ${ }^{7}$ Success rate observed in the study was $86.3 \%$ at one year follow up with mean hospital stay of 4.1 days. All Urodynamic parameters related to voiding dysfunction showed an improvement after the surgery. Richter HE et al. studied 292 women of Stress Incontinence and observed a success rate of $80.8 \%$ with TOT while patient's satisfaction rate was $90 \% .^{6}$ Post-op pain and UTI was observed in $2 \%$ cases each while voiding dysfunction was noted in none. The treatment success rates observed in present study is also similar to the rates reported in a recent Cochrane review. ${ }^{8}$ (84\%) and in two other metaanalyses. ${ }^{9,10}$ Similar lower complication rate in TOT was also observed by Barber et al. and Whiteside et al. in their studies. ${ }^{11,12}$

\section{CONCLUSION}

The present study concludes that TOT is a procedure requiring minimal dissection thus minimal blood loss, still effective enough to cure incontinence symptoms, provided case selection is proper. In experienced hands, it is a very safe surgery with very less number of bladder and urethral injuries. TOT is equally effective alone and in combination of any mode of hysterectomy, provided the surgeon is experienced enough with required expertise.

Funding: No funding sources

Conflict of interest: None declared

Ethical approval: The study was approved by the Institutional Ethics Committee

\section{REFERENCES}

1. Magon N, Kalra B, Malik S, Chauhan M. Stress urinary incontinence: What, when, why, and then what? Journal of mid-life health. 2011;2(2):57.

2. Wu JM, Kawasaki A, Hundley AF, Dieter AA, Myers ER, Sung VW. Predicting the number of women who will undergo incontinence and prolapse surgery, 2010 to 2050. Obstet Gynecol. 2011;205(3):230-35.

3. Weber AM, Abrams P, Brubaker L, Cundiff G, Davis $\mathrm{G}$, Dmochowski RR, et al. The standardization of terminology for researchers in female pelvic floor disorders. IntUrogynecol J Pelvic Floor Dysfunct. 2001;12(3):178-86.

4. Segal S, Arya LA, Smith AL. Functional Outcomes for Incontinence and Prolapse Surgery. Current bladder dysfunction reports. 2012;7(3):179-86.

5. Delorme E. Transobturator urethral suspension: miniinvasive procedure in the treatment of stress urinary incontinence in women. ProgUrol. 2001;11:1306-13.

6. Richter HE, Albo ME, Zyczynski HM, Kenton K, Norton PA, Sirls LT, et al. Retropubic versus 
transobturatormidurethral slings for stress incontinence. N Engl J Med. 2010;362(22):2066-76.

7. Lo TS. Combined pelvic reconstructive surgery and transobturator tape (monarc) in women with advanced prolapse and urodynamic stress incontinence: a case control series. Journal of Minimally Invasive Gynecology. 2009;16(2):163-8.

8. Ogah J, Cody JD, Rogerson L. Minimally invasive synthetic suburethral sling operations for stress urinary incontinence in women. Cochrane Database Syst Rev. 2009;4.

9. Novara G, Ficarra V, Boscolo-Berto R, Secco S, Cavalleri S, Artibani W. Tension-free midurethral slings in the treatment of female stress urinary incontinence: a systematic review and meta-analysis of randomized controlled trials of effectiveness. EurUrol. 2007;52:663-78.

10. Latthe PM, Foon R, Toozs-Hobson P. Transobturator and retropubic tape procedures in stress urinary incontinence: a systematic review and meta-analysis of effectiveness and complications. BJOG. 2007;114:522-31.

11. Barber MD, Kleeman S, Karram MM, Paraiso MF, Walters MD, Vasavada S, et al. Transobturator tape compared with tension-free vaginal tape for the treatment of stress urinary incontinence: a randomized controlled trial. Obstetrics \& Gynecology. 2008;111(3):611-21.

12. Whiteside JL, Walters MD. Anatomy of the obturator region: relations to a trans-obturator sling. IntUrogynecol J Pelvic Floor Dysfunct. 2004;15:223-6.

Cite this article as: Phulpagar A, Deshmukh PY. A prospective study of combination of TOT with various modes of hysterectomy. Int J Reprod Contracept Obstet Gynecol 2017;6:1240-3. 